\title{
Study of sodomy cases referred to medico legal department / Ministry of Justice in sohag in the period from january,2014 to january ,2017.
}

\author{
Mohamed Mostafa "Mohamed Kamel" , Maha Abd-Elhamed Helal , Ahmed \\ Mohamed Said and Walaa Ahmed El-Sayed .
}

Department of forensic medicine \& Clinical Toxicology, Faculty Of Medicine, Sohag University, Egypt

\section{Introduction}

Sodomy is defined as generally anal or oral sex between people or sexual activity between a person and animal, but it may also mean any non-procreative sexual activity, Sodomy is illegal in some countries and the law punish the sodomist, On the other side it's legal in other countries that have laws to regulate it (Scheb, 2013 ).

This abnormal sexual practice is popular allaround the world without any age limitation,involving adults, children and old subjects(Koerner and Brendan, 2002).

Sodomy is a sexual, social and religious crime, It refers to fail in all society institutions in taming the sexual desires ( Nandy, 1995 ).

The society exposes to a strong attack on the principles and morals due to absence of religious faith and absence of the role of the families in monitoring actions of their children ( Koerner and Brendan, 2002 ).

The unemployment is the mainly source in spreading of most sexual crimes because it leads to delay of age of marriage and increase of sexual desires which leads to abnormal sexual relationships ( Nandy, 1995 ).

Sodomy is a very dangerous crime due to many complications on sodomist and on the society ,These complications are psychic and health complications which lead to spread of dangerous diseases that destruct the community ( Koerner and Brendan, 2002 ).
It is very difficult to know exactly the real sodomy rate because most of victims refuse to inform the authorities fearing of scandals ( Parikh, 1995).

Strong family and good communication between father, mother and their children are the keys in struggling the sodomy ( Parikh, 1995) Sexual crimes are difficult crimes in dealing with them because they need long experience to understand different sexual behaviors, There are many factors that increase the difficulty of these crimes such as family and social complications and the interest in the media ( Markovchick and Vincent, 2016 ).

Many scientists have made researches aimed at studying the causes of sodomy and trying to find solutions and assessing the results( Smothers and Donovan, 2011).

In developing countries, Intervention occur only after the discovery of the problem of sodomy and not taken to advance the development of reliable strategies to prevent this problem and protect the community, Most of developed countries put many programs to struggle sodomy( Smothers and Donovan, 2011).

\section{Aim of the work :}

This work aims to study sodomy cases referred to medico legal department Ministry of Justice in sohag in the period from january,2014 to January ,2017 to find the relationship between sodomy and related factors and try to 
find strategies to solve this problem in sohag.

\section{Patients and methods :}

\section{Study design:}

A retrospective \&prospective study.

Subjects:

A total of 105 casesreferred to medico legal department, Ministry of Justice in SohagGovernoratein the period from january,2014 to January ,2017 will be included in the study.

\section{Methods:}

All of the participants will be subjected to the following:

1. Full history (demographic data and personal history, detailed history of general health condition and chronic or current diseases).

2. We will take inconsideration relationship between sodomy and sex, age, residence, marital status, socio-economic status, education level and relationship between victim and perpetrator.

3. Examination of clothes of victim wearied at time of the crime .

4. Viewing all the papers related to the crime.

5. General and local examination for signs of sodomy.

6. The data will be collected and suspected to statistical analysis for finding relationships.

\section{Ethical considerations:}

\section{Discussion}

Sodomy is defined as generally anal or oral sex between people or sexual activity between a person and animal, but it may also mean any non-procreative sexual activity, Sodomy is illegal in some countries and the law punish the sodomist, On the other side it's legal in other countries that have laws to regulate it (Scheb, 2013 ).

This abnormal sexual practice is popular allaround the world without any age limitation,involving adults, children and old subjects(Koerner and

Brendan, 2002).
- The study was approved by the Scientific Ethical Committee of Faculty of Medicine, Sohag University.

- An informed written consent was taken from all of the participants in the study.

\section{Statistical analysis:}

ßStatistical package for social sciences (IBM-SPSS), version 24 (May 2016); IBM- Chicago, USA will be used for statistical data analysis.

BData will be expressed as mean, median, minimum, maximum, standard deviation (SD), frequencies, number and percentage. Mean and standard deviation will be used as descriptive value for quantitative data.

ß(ANOVA ) test will be used to compare means of more than two groups.

BStudent $t$ test will be used to compare the means between two groups.

ßPearson Chi square test will be used to compare percentages of qualitative variables.

ßFor all these tests, the level of significance (P-value) can be explained as:

1. No significance $P>0.05$

2. Significance $P<0.05$

3. High significance $P<0.01$

4. Very high significance $\mathrm{P}<0.001$.

Sodomy is a sexual, social and religious crime,It refers to fail in all society institutions in taming the sexual desires ( Nandy, 1995 ).

The society exposes to a strong attack on the principles and morals due to absence of religious faith and absence of the role of the families in monitoring actions of their children ( Koerner and Brendan, 2002 ).

Sodomy is a very dangerous crime due to many complications on sodomist and on the society ,These complications are psychic and health complications which lead to spread of dangerous diseases that destruct the 
community ( Koerner and Brendan, 2002 ).

It is very difficult to know exactly the real sodomy rate because most of victims refuse to inform the authorities fearing of scandals ( Parikh, 1995 ). Strong family and good communication between father, mother and their children are the keys in struggling the sodomy ( Parikh, 1995 ).

Many scientists have made researches aimed at studying the causes of sodomy and trying to find solutions and assessing the results( Smothers and Donovan, 2011).

In developing countries, Intervention occur only after the discovery of the problem of sodomy and not taken to advance the development of reliable strategies to prevent this problem and protect the community, Most of developed countries put many programs to struggle sodomy( Smothers and Donovan, 2011).

Aim of this study was to study sodomy cases referred to medico legal department Ministry of Justice in sohag in the period from january, 2014 tojanuary, 2017 to find the relationship between sodomy and related factors and try to find strategies to solve that problem in sohag.

This study included 105 cases, including $66.7 \%$ males and $33.3 \%$ females, the victims and perpetrator were $41.0 \%$ from urban and $59 \%$ from rural areas.Regarding marital Status, $85.7 \%$ of perpetrators weresingle and $14.3 \%$ were married. The victims were $100 \%$ single, however in study of $\boldsymbol{A l}$ Mahroos et al.,(2005), male and female victims are almost equal in number $(50.5 \%$ and $49.5 \%$, respectively). Our results was similar to study ofMaklad et al., (2006)as $54 \%$ of victims in their study were males, alsoMohamed et al., (1990)reported that 321cases of sexually abused boys were examined in the Medico-Legal department in Cairo during the period of 1986-1990.

Regarding gender of victims in this study, $66.7 \%$ were males and $33.3 \%$ were females. Contrasting with study of Madu and Peltzer, (2001) on South African students yielded the highest prevalence rate of sodomy in theirstudy. Furthermore, the prevalence rate found among their male subjects $(60 \%)$ was higher than that of their female subjects (53.2\%), however, other authors (Finkelhor, 1994; Wynkoop et al., 1995) argue that differences in research methodology account for most of the variance in prevalence rates between studies. In the study of Back et al., (2003), the ratio of female to male victims of sodomy in childhood ranges between .89 and 5.50, although most of the studies report ratios above 1 , thus illustrating the higher prevalence rates amongwomen(Bouvier et al., 1999; Briere\& Elliott, 2003; Robin et al., 1997). Several factors have been suggested to explain these results. Holmes and Slap, (1998)argue that males who have been sexually victimized may be reluctant to divulge their experiences. First, sexually victimized males may considerthat it is unmanly to seek help (Dhaliwal et al., 1996; Romano \& De Luca, 2001), since the abuse experience undermines many men's concepts of their masculinity (Holmes et al., 1997). It may also be that men are less likely to label clearly their childhood sexual activity as abusive, since their role in the ideology of sexual abuse has been that of victimizers (Holmes et al., 1997).

Mean age of the victims in this study was 11.19range from 8 to 16 years, mean age of the perpetrator was 22.73 , and range from 18 to 28 years. This was similar to study ofHilal et al., (2006)as age of victims in their study was between ages 12 and 18 years, also in study ofOlsson et al., (2008)66\% of 
victims were maleyounger than 12 years. These results are close to those of a study done in Tanzania that revealed that the mean age at which abuse occurs for males and females is similar at 13.5 and 13.8 years, respectively(McCrann et al., 2006).

Another study in El Salvador showed the mean age of child sexual abuse was 14 years(Barthauer and Leventhal, 1999). A study carried out on 87 cases of sexual assault in the Assiut Governorate from 2003 to 2007 showed that the highest percentage of cases was among the age group 15-18 (35 cases, 40.2\%) of which females represented 34 cases, followed by age group 5-9 (20 cases, 23\%) of which male represented 17 cases. Young males were often playing outdoors, not under the supervision of their families, Females of a young age group tend to stay at home close to their mothers(Thabet, 2008).

In a study done in Saudi Arabia on child abuse, about $15 \%$ were sexually abused in the period from 2000 to 2008. Thirty percent took place in the period from 2000 to $2004,10 \%$ in 2005 to 2006 , while $60 \%$ were in the period 2007 to 2008(Al Essa and $\boldsymbol{A l}$ Muneef, 2010).A study from United States of America revealed that children are responsible for $16.4 \%$ of rapes and $18.6 \%$ of other sexual offenses as sodomy. Additionally, $6.4 \%$ of rapes and $9.7 \%$ of other sexual offenses are committed by children less than 15 years of age. There are offenders even as young as 10 years old (Becker and Hicks, 2003). In USA, of all children and adolescents who were charged with committing sexual assault, $28 \%$ were between 12 to 14 years, $37 \%$ were between 15 to 17 and the remaining $42 \%$ were between 18 to 20 years of age (Pratt et al., 2007, Burton, 2000). Regardingeducation level, $80 \%$ of perpetrators were low education level, $20 \%$ werehigh education level. This was similar to study of Heise et al., (2006) as $82 \%$ of the perpetrator were low educational level and $18 \%$ were high educational level.Another study indicated the low educational level of mothers of adolescent sexual offenders (Al Essa and Al Muneef, 2010). Accordingly, a study from Turkey also revealed low educational levels of parents and socioeconomic levels of families (Göker et al., 2009). Studies suggesting broken families as the key risk factors showed that overwhelming majority of child sexual offenders were living with only one parent, while only $16-30 \%$ of the offenders were from intact nuclear families (Kahn and Chambers, 1991). Another study revealed that half of the offenders were from intact families (Pratt et al., 2007).In a Canadian study, Allagia, (2010) describe how families that experience child sexual crimes incidents may also experience intimate partner violence. In these families, the sexually abused children encounter difficulties in disclosing the abuse to their mothers, who are facing violation by the same perpetrator. The same study (Allagia, 2010)describes how non-disclosure might occur to preserve family integrity when intrafamily sexual abuse is identified. Such barriers to disclosure are referred to as "micro-system level factors" (family environment factors). Finkelhor et al., (2001).

Regarding socioeconomic level of victims, $\quad 88.57 \%$ were low socioeconomic level, $11.43 \%$ were high socioeconomic level. This was similar to study ofBarthauer and Leventhal,(1999). As $89.5 \%$ of victims were low socioeconomic level, $10.5 \%$ of victims were high socioeconomic level.

Regarding socioeconomic level of perpetrators, $81.9 \%$ were low socioeconomic level, $18.1 \%$ were high socioeconomic level. This was similar to study ofBarthauer and Leventhal, 
(1999). As $80.5 \%$ of perpetrators were low socioeconomic level, $19.5 \%$ of perpetrators were high socioeconomic level.

Theseobservations reflect that although lower socioeconomic status might put children at higher risk of sodomy, higher socio-economic status does not guarantee the child's safety(Barthauer and Leventhal, 1999).

Child sexual offenders are reported to suffer from certain problems during their educational life. The literature revealed that they have at least one of the problems out of inappropriate behaviors, nonattendance and learning difficulties. Therefore, approximately half of child sexual offenders fail their class at least once. In accordance with the literature, similar problems and interruption of education were observed to be common in our series, as well(Kahn and Chambers, 1991).

Another study showed that sexual offenders have an IQ slightly under average values. Mild and moderate mentally retarded offenders were prone to commit non-violent acts (Ferrara and McDonald, 1996; McCurry et al., 1998).

Children may be sexually abused by family membersornonfamily members. Regarding relationship between the victim and the perpetrator we found that, $14.3 \%$ were strange, $25.7 \%$ relatives and $60 \%$ were friends, also study ofOlsson et al., (2008)in a Nicaragua as the most common perpetrators of abuse on children were family members including uncles, cousins, and fathers (66\%); other studies on perpetrators of sodomy showed that the vast majorityof perpetrators were male and known to the victim or family(Heise et al., 1999; Jejeebhoy and Bott, 2008), This was similar to study of (Barthauer and Leventhal, 1999), $15 \%$ were strangers, Regarding comparison between ages of the victim with ages of the perpetrator,
$27 \%$ were relatives and $58 \%$ were friends. Contrasting with result of study of Chen et al., (2006), 82\% were strangers, $7 \%$ were relatives and $11 \%$ were friends.Another researcher stated that about $30 \%$ of all perpetrators of sexual abuse are related to their victims; $60 \%$ of the perpetrators are family acquaintances such as a neighbor, babysitter, or friend and $10 \%$ of the perpetrators in child sexual abuse cases are strangers(Joan, 2005). Prevalence of parental child sexual abuse is difficult to assess due to secrecy and privacy; some estimates show 20 million Americans have been victimized by parental incest as children(Turner and Jeffrey, 1996).

However, in a study in Israel, the majority of perpetrators were strangers, and the intra-family abuse was more common in females than in males(Chein et al., 2000).In the study of Wijk et al.,(2006), $8.6 \%$ of cases reported sexual assault combined with physical assault, while $3.9 \%$ reported armed threat. There was a similarity between their study and a study in Tanzania that documented almost $13 \%$ of females mentioned physical force as a major form of persuasion(Wijk et al., 2006). Canadian incidence study revealed that genital touching and fondling $(62.5 \%)$ was the most common form of child sexual abuse and followed by sodomy in $39 \%$ of the children(Public Health Agency of Canada, 2010). A qualitative study among survivors in Israel established shame and stigma as barriers to sexual abuse disclosure. When the perpetrator is familiar, the cases are especially unlikely to reach the legal system. Researchers established that such families are often closed systems, characterised by chaos and isolation (Hershkowitz et al., 2007).

there is significant difference between the age of the victim and age of 
perpetrator with $\mathrm{P}$ value $<0.001$ (VHS).

The average age of the victim is 11.19 \pm 2.47. The average age of the perpetrator is $22.73 \pm 3.27$.

Regarding comparison between residence of the victim\& residence of the perpetrator, the majority of cases were rural, and there is significant difference between the two groups regarding residence as the $\mathrm{p}$ value $=$ $<0.001$ (VHS). Regarding victims, $41 \%$ of victims were urban,59\% were rural. Regarding perpetrators, $41 \%$ were urban, $59 \%$ were rural.

Regarding comparisonbetween socioeconomic levelof the victim\& socioeconomic level of the perpetrator,the majority of cases were low socioeconomic, and there is significant difference between the two groups regarding socioeconomic level as the $\mathrm{p}$ value $=<0.001$ (VHS). Regardingvictims, $88.57 \%$ were low socioeconomic level, $11.43 \%$ were high socioeconomic level. Regarding perpetrators, $81.9 \%$ were low socioeconomic level, $18.1 \%$ were high socioeconomic level.

\section{Recommendations :}

1) Sodomy is a major sexual, social and religious crime.

2) Early detection and early management of sodomist is very important in struggling the sodomy.

3) Strong family is the most important key to prevent the sodomy.

4) Our study recommend putting many strategies to struggle the sodomy and doing more studies over a wide scale of cases.

\section{References}

1. Al Essa, M. and Al Muneef, M. (2010): Child abuse and neglect in Saudi Arabia. Journal Of Recognition To Implementation Of National Prevention Strategies, 34:28-33.

2. Al-Mahroos, F; Abdulla, F; Kamal, $S$; and Al-Ansari, A. (2005): Child abuse. Child Abuse and Neglect, 29:193-215.
3. Back, S; Jackson, L; Fitzgerald, M; Shaffer, A; and Salstrom, S. (2003): Child sexual and physical abuse among college students in Singapore and the United States. Child Abuse And Neglect, 27:1259-1275.

4. Barthauer, M. and Leventhal, $R$. (1999): Prevalence and effects of child sexual abuse in poor, rural community in El-Savador. Child Abuse, 23:117-126.

5. Becker, J. and Hicks, S. (2002):Caracteristics, Intervention and policy issues. Juvenile Sex Offenders, 19:397-410.

6. Besharov, R.C. and Douglas, A. (1998): The evaluation of suspended child physical abuse. Fixing Child Protection, 4:1337-1354 .

7. Burton, D. (2004): Were adolescent sexual offenders children with sexual behavior problems?. Sex Abuse, 20:37-48.

8. Chein, M; Biderman, A; Baras, M; Bennett, L; and Bisharat, B. (1999): The prevalence of a history of child sexual abuse among adults visiting family practitioners. Child Abuse Neglect, 24:667-675.

9. Chen, J; Dunne, M; and Han, P. (2006): Child sexual abuse in Henan province, China: Association with sadness, suicidality and risk behaviors among adolescent girls. Adolescence Health 38:201-220.

10. Dietz, P.E. (1990): The sexually sadistic criminal and his offenses. Journal Of Sex Research, 31:17-25 .

11. Downing, R.C. and Christine, M.A. (1994): Sexual attraction and behavior among lesbian and bisexual women. The Politics of Sexual Identity, 3:221231.

12. Fareena, $K$. (2012): Homosexuality and the shariat. Journal Of Arabic And Islamic Studies, 41:16-28 .

13. Ferrara, $M$. and McDonald, $S$. (1998): Treatment of the Juvenile Sex Offender: Neurological and Psychiatric Impairments. Sexual 
Behavior And Personality, 25:128139.

14. Finkelhor, D; Turner, H; Ormrod, $R$; and Hamby, S. (2010): Trends in childhood violence and abuse exposure. Arch PediatrAdolesc Med, 164:238-42.

15. Finkelhor, D; Wolak, J; and Berliner, L. (2001): Police reporting and professional help seeking for child crime victims. Child Maltreat, 12:17-30.

16. Finkelhor, D. (1994): The international epidemiology of child sexual abuse. Child Abuse \& Neglect, 18:409-417.

17. Göker, Z; Aktepe, E; Hesapçığlu, T; and Kandil, S. (2009): Children and Adolescents as Sexual Offenders. KlinikPsikiyatriDergisi, 12:141-156.

18. Heise, L; Ellsberg, $M$; and Gotemoeller, M. (1999): Ending violence against women. Johns Hopkins University School of Public Health, Population Information Program, 7:111-122.

19. Hilal, M; Mohamed, S; and Aboul-Hagag, K. (2002-2003): Sexual assaults in Sohag Governorate in two years (20022003). Sohag Med J, 10:264-274.

20. Hines, C. and Melissa, J. (2011): Prenatal endocrine inflounces on sexual orientation and on sexually differentiated childhood behavior. Sexual Orientation, 11:170-187 .

21. Holmes, G; Offen, L; and Waller, G. (1997): See no evil, hear no evil, speak no evil: Why do relatively few male victims of childhood sexual abuse receive help for abuse-related issues in adulthood? Clinical Psychology Review, 17:69-88.

22. Holmes, W. and Slap, G. (1998): Sexual abuse of boys. Definition, prevalence, correlates sequelae, and management. Journal of The American Medical Association, 51:18-27.
23.Kahn, T. and Chambers, $H$. (1991): Assessing reoffense risk with juvenile sexual offenders. Child Welfare, 11:333-345.

24. Lisa, J. and Padmal, D.S . (2009): Psychopathology and personality trials of pedophiles, Sexual Disorder And Psychosexual Therapy, 2:125-151 .

25. Lyman, N. and Michael,R. (2006): Drugs and sexual assault. Practical Drug Enforcement, 7:210-251.

26. Madu, S. and Peltzer, K. (2001): Prevalence and patterns of child sexual abuse and victim-perpetrator relationship among secondary school students in the Northern Province (South Africa). Archives of Sexual Behavior, 30:311-321.

27. Maklad, A; El-Mehy, I; and ElShazly, M. (2006): A medico-legal study of sexual offences in Dakahlia Governorate. Zagazig J Forensic Med Toxicol, 4:75-94.

28. Markovchick, J.C. and Vincent, A.G. (2016): Sexual assult. Archives Of Sexual Behaviors, 24:516-532.

29. McCrann, D; Lalor, K; and Katabaro, J. (2006): Childhood sexual abuse among university students in Tanzania. Child Abuse Negl, 30:343-351.

30. Mohamed, F; Tawfik, $N$; and ElDin, R. (1990): Sexual abuse of boys in Cairo 1986-1990. MJFMCT, 3:83-96.

31. Nandy, A. (1995):Forensic and medico-legal aspect of sexual crimes and unusual sexual practices. Principles Of Forensic Medicine, 17:110-123.

32. Olsson, A; Ellsberg, E; Berglund, $S$; Herrera, A; Zlaya, E; and Pena, R.(2008): Sexual abuse during childhood and adolescence among Nicaraguan men and women: a population based anonymous survey. Child Abuse Negl, 24:79-91. 
SOHAG MEDICAL JOURNAL Study of sodomy cases referred to medico legal department

33. Parikh, C. (1995):Immediate medical care after sexual assault. Parikh's Textbook Of Medical Jurisprudence And Toxicology, 5:457-469.

34. Patrek, M.B. (2003): The trauma of sexual assault, treatment and prevention. Homosexual Couples And Violence, 3:439-462 .

35. Pratt, H; Greydanus, D; and Patel, D. (2007): The adolescent sexual offender. Prim Care, 34:305-316.

36. Richard, A.K . (1999): Acute stress disorder. Abnormal Psychology, 9:1780-1799 .

37. Romano, E.and De Luca, R. (2001): Male sexual abuse: A review of effects, abuse characteristics, and links with later psychological functioning. Aggression And Violent Behavior, 6:55-78.
38. Scheb, J. (2013): Definition of sodomy. Criminal Law And Procedure, .7:185-190 .

39. Smothers, M.K. and Donovan, N. (2011): A sexual assault primary prevention. Gay Couples, 21:708-727 .

40. Thabet, H. (2008): Assessment of sexual assault cases in Assiut Governorate. Egypt J Forensic SciApplToxicol, 8:22-32.

41. Wynkoop, T; Capps, S; and Priest, B. (1995): Incidence and prevalence of child sexual abuse: A critical review of data collection procedures. Journal of Child Sexual Abuse, 4:49-67. 